University of Nebraska - Lincoln

DigitalCommons@University of Nebraska - Lincoln

Sociology Department, Faculty Publications

Sociology, Department of

2-2005

\title{
Child Neglect and Adolescent Violence: Examining the Effects of Self-Control and Peer Rejection
}

\author{
Constance L. Chapple \\ University of Nebraska-Lincoln, cchapple@unlserve.unl.edu \\ Kimberly A. Tyler \\ University of Nebraska-Lincoln, kim@ktresearch.net \\ Bianca E. Bersani \\ University of Nebraska-Lincoln, bbersani@umd.edu
}

Follow this and additional works at: https://digitalcommons.unl.edu/sociologyfacpub

Part of the Sociology Commons

Chapple, Constance L.; Tyler, Kimberly A.; and Bersani, Bianca E., "Child Neglect and Adolescent Violence: Examining the Effects of Self-Control and Peer Rejection" (2005). Sociology Department, Faculty Publications. 67.

https://digitalcommons.unl.edu/sociologyfacpub/67

This Article is brought to you for free and open access by the Sociology, Department of at DigitalCommons@University of Nebraska - Lincoln. It has been accepted for inclusion in Sociology Department, Faculty Publications by an authorized administrator of DigitalCommons@University of Nebraska - Lincoln. 


\title{
Child Neglect and Adolescent Violence: Examining the Effects of Self-Control and Peer Rejection
}

\author{
Constance L. Chapple, PhD \\ Kimberly A. Tyler, PhD \\ Bianca E. Bersani, MA \\ University of Nebraska-Lincoln
}

\begin{abstract}
Child maltreatment researchers have often suggested that experiences with child neglect have long-term, negative effects. Child neglect is thought to have particularly adverse effects on self-control, peer relations, and delinquency. In this research, we examine the relationship of child neglect with adolescent violence via self-control and peer rejection. Using prospective, longitudinal data from a community sample, we find that child neglect adversely affects peer rejection and violence. Neglected children were more likely to be rejected by their peers in early adolescence and were more likely to be violent later in adolescence. Contrary to theoretical predictions, child neglect was not a significant predictor of self-control. Implications for delinquency and child maltreatment researchers are discussed.
\end{abstract}

Keywords: neglect, self-control, violence, peer rejection

$\mathrm{D}$ elinquency researchers have long been interested in familial processes and delinquency. In particular, much attention has been paid to the effect of physical abuse on delinquency (Doerner, 1988; McCord, 1983; Widom, 1989). Comparatively little research has been done however, on the deleterious effects of early childhood neglect on adolescent delinquency. While it is well established that domains of child maltreatment overlap (Ireland, Smith, \& Thornberry, 2002; Smith \& Thornberry, 1995; Stouthamer-Loeber, Wei, Homish, \& Loeber, 2002; Zingraff, Leiter, Meyers, \& Johnsen, 1993), little empirical attention has been paid to the relationship between the absence of parenting, or child neglect, on delinquency. Those studies that examine the differential effects of various types of child maltreatment on delinquency find that neglected children have higher rates of violence, property crime, and general delinquency than physically abused children (Zingraff et al., 1993) or have similar rates of delinquency compared to physically abused children (McCord; Widom).

Experience with maltreatment in childhood has been suggested to interfere with healthy emotional and behavioral development (Egeland, Yates, Appleyard, \& van Dulman, 2002; Ireland et al., 2002; Maughan \& Cicchetti, 2002), including developing healthy peer relations (Bolger \& Patterson, 2001; De Paul \& Arruabarrena, 1995; Mueller \& Silverman, 1989) and the development of self-control (Avakame, 1998; Gottfredson \& Hirschi, 1990). As such, neglected children experience limited parent-child 
interactions, which are often devoid of attention and caring, and subsequently are unlikely to have the ability to regulate their emotions, curb impulsivity, or choose appropriate peers. Much of the current research on child maltreatment and delinquency has focused on the nature of maltreatment and/or the chronicity of maltreatment as predictors of serious and chronic delinquency (Ireland et al.; Smith \& Thornberry, 1995). This prior research finds that chronically maltreated youths are more likely to be serious delinquents (Smith \& Thornberry; Zingraff et al., 1993) than children with less persistent maltreatment.

Often overlooked in this line of research is the process through which maltreatment, and specifically child neglect, impacts adolescent outcomes such as self-control, peer rejection, and ultimately, delinquency. Neglected children, whether episodically or chronically neglected, are unlikely to develop the ability to resist criminal temptations and defer gratification and may be rejected by conventional peers. Using a prospective, longitudinal, community sample of mothers and their children, we add to the growing list of research on child maltreatment and delinquency by examining the process through which childhood neglect impacts adolescent delinquency via selfcontrol and peer rejection.

\section{Literature Review}

\section{Child Maltreatment and Delinquency}

Research on child neglect and delinquency (Lemmon, 1999; Luntz Weiler \& SpatzWidom, 1996; Stouthamer-Loeber et al., 2002; Zingraff et al., 1993) suggests that neglected children are often as likely to be involved in delinquency as other maltreated children (Lemmon, 1999). Child neglect and its effect on delinquency however, is rarely assessed independent of other types of child maltreatment, and it is difficult to discern to what extent child neglect impairs adolescent development and increases the likelihood of delinquency. Additionally, research on child neglect and delinquency has been limited primarily to research on officially recorded neglected children (Lemmon, 1999; Luntz Weiler \& Spatz-Widom, 1996; Stouthamer-Loeber et al., 2002; Zingraff et al., 1993), leaving open questions concerning the effects of neglect for children who are not severely neglected or escape state notice. Developmental research on neglect in early childhood suggests that children who are neglected prior to the preschool years have particularly adverse developmental outcomes in childhood and adolescence, although prospective longitudinal research on the adverse effects of child maltreatment into adolescence is rare (Hildyard \& Wolfe, 2002; Scannapieco \& Connell-Carrick, 2002). Because the bulk of the research on child neglect combines measures of neglect with other measures of maltreatment, we review the general child maltreatment and delinquency relationship below.

Research on child maltreatment and delinquency often finds that abused and/ or neglected children are more likely to be serious delinquents (Smith \& Thornberry, 1995; Stouthamer-Loeber et al., 2002), engage in violence (Benda \& Corwyn, 2002; Kruttschnitt, Ward, \& Sheble, 1987; Raskin White \& Spatz Widom, 2003), or be arrested (Smith \& Thornberry, 1995; Zingraff et al., 1993) than nonmaltreated youths. These delinquent outcomes are more likely among children who have been chronically maltreated (Ireland et al., 2002). Research indicates a clear link between child maltreatment and delinquency, but methodological flaws have plagued this area. Some research utilized very small samples, making the generalizability of findings uncertain, while other research on child maltreatment and delinquency did not include control groups of nonmaltreated youth. Recent research has rectified many of these methodological problems, and the connection between maltreatment and se- 
rious delinquency appears clear (Ireland et al., 2002; Raskin White \& Spatz Widom, 2003). However, researchers have issued recent calls for research on maltreatment that utilizes community samples and self and observer reports of child neglect (Gershater-Molko, Lutzker, \& Sherman, 2003).

Research also suggests that delinquency varies by types of maltreatment. Although the trend is that types of maltreatment generally overlap (e.g., neglected children are often physically abused), research that does distinguish between types of maltreatment finds that physically abused and/or neglected children are often most seriously delinquent (Kruttschnitt et al., 1987; Smith \& Thornberry, 1995; Zingraff et al., 1993). Researchers have investigated potential explanations for the connection between maltreatment and delinquency. They have found that maltreatment was tied to poor social controls (Brezina, 1998; Herrenkohl, Huang, Tajima, \& Whitney, 2003), poor emotional regulation (Maughan \& Cicchetti, 2002), and the acquisition of deviant values (Brezina; Herrenkohl et al.). Additionally, the relationship between child maltreatment and delinquency was stronger for children in nonintact homes (Stouthamer-Loeber et a]., 2002), and the relationship was mediated by attachment to mother (Benda \& Corwyn, 2002), good school performance (Zingraff, Leiter, Johnsen, \& Myers, 1994), and family structure (Zingraff et al.). Although theorists and researchers have often suggested that experiences with maltreatment in childhood adversely affect child and adolescent development (Egeland et al., 2002; Hildyard \& Wolfe, 2002), little research has been done to corroborate this assertion with longitudinal data into adolescence. To fully understand the long-term consequences of maltreatment, we need to examine how maltreatment affects development and delinquency in adolescence.

\section{Poor Parenting and Self-Control}

Developmental researchers have long asserted that child neglect is tied to poor emotional regulation (Egeland et al., 2002; Maughan \& Cicchetti, 2002), antisocial personality (Horowitz, Spatz Widom, McLaughlin, \& Raskin White, 2001; Raskin White \& Spatz Widom, 2003), and impulsivity Hildyard \& Wolfe, 2002), constructs similar to the concept of self-control in criminology. According to Gottfredson and Hirschi, in A General Theory of Crime (1990), self-control is the differential tendency of people to avoid criminal acts regardless of the circumstances in which they find themselves. Youths lacking in self-control will tend to be impulsive, insensitive, physical (as opposed to mental) risk-taking, shortsighted, and nonverbal, and they will therefore tend to engage in criminal and analogous acts (p. 90). Those with low self-control have difficulty managing their emotions, act without thinking, and often disregard the pain and suffering in others. According to Gottfredson and Hirschi, low self-control is not produced by socialization or learning but by the absence of nurturance, discipline, or training (p. 95). In order for self-control to develop, someone must care about the child (attachment), watch the child (supervision), and recognize and punish deviant behavior when it occurs (discipline). Children who are neglected are devoid of parental caring and interaction and are unlikely to develop self-control, and would be more likely to engage in delinquency.

Empirical research has confirmed Gottfredson and Hirschi's assertions that attached, consistent parenting is tied to self-control (Gibbs, Geiver, \& Martin, 1998; Hope, Grasmick, \& Pointon, 2003), while poor monitoring and weak discipline often inhibit the development of self-control (Hope et al.; Unnever, Cullen, \& Pratt, 2003). Gottfredson and Hirschi also maintain (1990, p. 101) that parental deviance will adversely affect children's self-control, and research has shown that early maternal sexual behavior (Hope \& Chapple, 2004), interparental violence (Avakame, 1998), and maternal substance use (Chapple, Hope, \& Whiteford, 2004) are linked with chil- 
dren's low self-control. Finally, child neglect (Coulton, Corbin, \& Su, 1999; Gabarino \& Sherman, 1980; Hildyard \& Wolfe, 2002) and self-control (Hope et al.; Paternoster \& Brame, 1997) are often associated with growing up in poor, single-parent families, and controlling for family and structural context is particularly important when examining the relationship between child neglect and self-control.

\section{Child Maltreatment and Negative Peer Relations}

Parents play a key role in helping children form positive relationships with peers (Bolger \& Patterson, 2001), and positive peer relations are important because they contribute to competence and advancement of social skills, and help aid in the development of forming positive relations with others (Mueller \& Silverman, 1989). Maltreated children often have problems with peer relations because they tend to be more aggressive and socially withdrawn (Bolger \& Patterson, 2001; De Paul \& Arruabarrena, 1995; Mueller \& Silverman), and children displaying these characteristics are more likely to be rejected by their peers (cf. Bolger \& Patterson; Rubin, LeMare, \& Lollis, 1990). Numerous studies have found that aggressive behavior leads to unpopularity of maltreated children as well as rejection by normal peer groups (Bolger \& Patterson, 2001; Coie, Dodge, Terry, \& Wright, 1991; Little \& Garber, 1995; Patterson, Dishion, \& Bank, 1984; Pope \& Bierman, 1999). Rejection by prosocial peers is problematic given that it is a major risk factor for poor adjustment and has been associated with delinquency at later developmental stages (Bolger \& Patterson, 2001; Coie \& Cillessen, 1993; Patterson, DeBaryshe, \& Ramsey, 1989; Whitbeck \& Hoyt, 1999).

Despite the significant increase in emotional and physical neglect in recent years (Sedlak \& Broadhurst, 1996), child neglect has received limited attention in the literature (Crouch \& Milner, 1993; De Paul \& Arruabarrena, 1995). The few studies on neglect that do exist, however, have found a positive link between neglect and peer rejection (Bolger \& Patterson, 2001; Bolger, Patterson, \& Kupersmidt, 1998; De Paul \& Arruabarrena, 1995). Among a representative community sample of maltreated and nonmaltreated children, Bolger and Patterson found that chronic maltreatment (which included neglect) was associated with a higher risk of rejection by peers. The duration of maltreatment also positively influenced the child being rejected by peers over time. Both neglected and physically abused children had more problems establishing relations with peers, and both groups had higher rates of delinquent behaviors compared to their nonabused counterparts (De Paul \& Arruabarrena, 1995). Overall, research tends to find that children who are subjected to all forms of maltreatment have poorer outcomes compared to nonmaltreated children (Kaufman \& Cicchetti, 1989; Manly, Cicchetti, \& Barnett, 1994) and, as a result, are likely to have unsuccessful encounters with peers. Additionally, Bolger and colleagues (1998) argue that the physical environments of neglectful families (e.g., homes being extremely dirty) may discourage children from inviting friends over, which may contribute to a lack of friends among neglected children. Those children who have difficulties establishing and maintaining relationships with prosocial peers are more at risk of becoming delinquent later in life (De Paul \& Arruabarrena, 1995; DeMuth, 2004).

Although preliminary research indicates that there is an important connection between child neglect and delinquency, additional studies are needed that fully examine this link. In particular, theorists and researchers in child maltreatment have called for the use of noninstitutionalized, community samples and for researchers to use longitudinal samples that extend into adolescence. We add to the growing list of research on child neglect by utilizing a longitudinal, national, community sample of mothers and their children, with self- and observer reports of child neglect, to assess the effects of early childhood neglect on self-control, peer rejection, and adolescent delinquency. 
Table 1. Descriptive Information for the Sample $(N=942)$

\begin{tabular}{lcc}
\hline & $\mathrm{M}$ & $\mathrm{SD}$ \\
\hline Race $(0=$ White, $1=$ non-White $)$ & 0.477 & 0.499 \\
Sex $(0=$ female, $1=$ male $)$ & 0.485 & 0.500 \\
Age in 2000 $(15-17)$ & 16.0 & 0.820 \\
Family's poverty status in 1987-88 $(0=$ never, $1=$ ever $)$ & 0.328 & 0.470 \\
Family structure 1988 $(0=$ other, $1=$ intact $)$ & 0.591 & 0.479 \\
Spanked in the last week 1988 $(0=$ no, yes $=1)$ & 0.648 & 0.440 \\
Physical neglect $(0-3)$ & 2.76 & 0.557 \\
Emotional neglect $(0-2)$ & 1.80 & 0.462 \\
Educational neglect $(0-9)$ & 6.90 & 1.52 \\
Self-control $(7-21)$ & 17.9 & 2.45 \\
Peer rejection $(2-6)$ & 2.45 & 0.776 \\
Violence $(0-2)$ & 0.438 & 0.704 \\
\hline
\end{tabular}

\section{Methods}

\section{The Sample}

Data for this study were taken from the Children of the National Longitudinal Survey of Youth (NLSY-Child). The original National Longitudinal Survey of Youth (NLSY79) was a nationally representative longitudinal sample of youth aged 14 to 21 in 1979. The NLSY79 contains extensive information about the employment, education, training, and family experiences of the respondents (Center for Human Resource Research [CHRR], 2000, p. 1). Beginning in 1982, the female respondents of the NLSY79 were surveyed about pregnancy, postnatal fertility, and child care experiences (CHRR, p. 1). Since 1986, assessments of the children born to the women of the NLSY79 have been conducted. In 1994, children aged 15 and older were no longer assessed with their mothers, but instead completed individual, personal interviews that focused on a variety of attitudes and behaviors.

The NLSY79 Child sample approximately represents a cross section of children born to a nationally representative sample of women who were between the ages of 31 and 38 on January 1, 1998 (CHRR, 2000, p. 3). ${ }^{1}$ For the analyses, we combine data from mothers in 1988 when the children were aged 3 to 5, data from the mother and child assessments taken when the children were aged 11 to 13 in 1996, and data when the young adults were aged 15 to 17 in 2000 . The exogenous (independent) variables were measured in 1988, while the endogenous (dependent) variables were measured in 1996 (e.g., self-control and peer rejection) and 2000 (e.g., violence). This original sample violates independence assumptions as siblings were included in the sample. To rectify this, we randomly selected one respondent out of each sibling pair for inclusion in the sample. We deleted 133 siblings and 5 respondents with missing data on violence, for a final sample size of 942 young adults in 2000. We used structural equation models analyzed in AMOS (Arbuckle \& Worthke, 1999) to investigate the simultaneous direct and indirect effects of self-control and association peer rejection on violence. AMOS uses full information maximum likelihood (FIML) for the estimation of missing data. ${ }^{2}$ Descriptive information for our sample is presented in Table 1. 


\section{Measures}

\section{Independent Variables}

In the analyses we independently assess the effect of educational neglect, physical neglect, and emotional neglect, net of the effects of self-control, peer rejection, spanking, and demographic variables including gender, race, age, family structure, and poverty status.

All of the neglect and demographic measures were measured when the children were 3 to 5 years old in 1988. The measures of child neglect were taken from HOMESF (short form) assessments and are either mother self-reports or are observer reports of maternal behavior. Educational neglect was measured using five items assessing whether family members help the child to learn: numbers, the alphabet, sizes, colors, or none of these items, and how often the mother reads to the child each week. Items about learning/teaching were coded $0=$ no and $1=$ yes, and "how often mom reads to child" was coded as $0=$ never, $1=$ several times per year, $2=$ several times per month, $3=$ once a week, $4=$ about three times per week, and $5=$ every day. The five items were summed to form a composite scale of educational neglect, ranging from 0 to 9 . The scale is coded so that low values indicated educational neglect. The scale has a mean of 6.90, indicating low levels of educational neglect. Emotional neglect is an observer rating of mother and child interaction during the HOME-SF assessment. Observers/interviewers provided information on "whether the mother shows positive feelings in her voice when she talks about the child" and "whether the mother spoke to the child at least twice during the interview." These two items were measured as 0 $=$ no and $1=$ yes and were added together to form the measure of emotional neglect. Emotional neglect ranges in value from 0 to 2, with low values indicating emotional neglect. The mean for emotional neglect was 1.80 , suggesting that very few children in the sample were emotionally neglected in 1988.

Physical neglect is an observer rating of the home conditions of the child and is part of the overall HOME-SF scale. Interviewers recorded whether the interior of the residence appeared: safe, dark or monotonous, reasonably clean, and minimally cluttered. Responses are coded as $0=$ no and $1=$ yes. Principal components factor analysis suggested that all four items loaded on one factor, but reliability analysis suggested that deleting "minimally cluttered" increased the reliability of the scale. The three remaining items were summed to form a composite scale of physical neglect that has a reliability of .65. Physical neglect is coded so that low values on the scale indicate physical neglect. The item ranged from 0 to 3 with a mean of 2.76 , indicating a low level of physical neglect in the sample.

Because types of maltreatment overlap, it was important to control for the effects of physical abuse when assessing child neglect. Unfortunately, the NLSY-Child HOME instrument does not include measures of physical abuse, but it does include measures of corporal punishment. We use one measure of corporal punishment, "did you have to spank your child in the last week," as a rough proxy for physical abuse. The variable is measured as $0=$ no and $1=$ yes, with nearly $65 \%$ of the respondents reporting having spanked their child in the past week.

We used the following sociodemographic variables in the analysis: race, sex, age, family structure, and youth's family's poverty status from 1987 to 1988 . Gender is coded 0 for female and 1 for male, and race is coded 0 for White and 1 for non-White. Fifty-three percent of the sample was white, and 52\% percent of the sample was female. The sample ranged in age from 15 to 17 years old in 2000, with a mean of 16 years in 2000. Poverty status is a measure of the youth's family poverty status from 
the years 1987 to 1988. Because of problems with missing data and to maximize the number of respondents for analysis, we chose a narrow time frame of poverty when child neglect was measured to control for the confounding effect of poverty on child neglect. Responses range from 0 (never lived in poverty during these years) to 1 (lived in poverty during any of these years). The mean for poverty status was .328, indicating that 33\% of the mothers had lived in poverty from 1987 to 1988 . Family structure is a composite variable that measures whether children lived with both biological parents in 1988 (coded as 1) or in other familial arrangements (coded as 0). The mean for family structure is .591 , indicating that $59 \%$ of children lived with both biological parents in 1988. None of the independent variables are correlated beyond .35, and we do not have a problem with multicollinearity.

\section{Dependent Variables}

Because of the conventions of structural equation modeling analysis in AMOS, intervening variables (self-control and peer rejection) as well as dependent variables (violence) are considered endogenous variables. Therefore, we describe the measurement of self-control, peer rejection, and violence in this section.

The measures of self-control were taken from the 1996 NLSY-Child assessment when the children were between the ages of 11 to 13. The mothers of the children in the sample assessed their children on a series of attitudinal and behavioral measures of problem behavior and self-control. This is the third use of parental reports of children's self-control in the literature testing the general theory of crime using the NLSY79 and NLSY-Child data (see also Turner \& Piquero, 2002; Hope \& Chapple, 2004). ${ }^{3}$ Parents' reports of children's self-control should be conservative estimates of children's actual low self-control as parents may underestimate the extent to which their children are "problematic" or may not be aware of most or all of their children's problem behavior. The general "Behavioral Problems Index" (BPI) from which we took the self-control items has been validated and used extensively in developmental literature (CHRR, 2000). Descriptions of the items comprising the self-control scale are listed in the Appendix.

The 11 items within the BPI that measured self-control were entered into a principal components factor analysis with varimax rotation. One factor emerged. The 7 items that had factor loading scores higher than .45 (Tabachnick \& Fidell, 1997, p. 677) comprise the self-control scale and measure impulsivity, insensitivity to others, and incorrigibility. The alpha reliability of this scale is .77. The mean for self-control was 17.9 , with a range of 7 to 21 , indicating that the sample had relatively high levels of self-control.

Peer rejection was measured by two items in which the mothers were asked how true it was that their child "has trouble getting along with other children" and "is not liked by other children." Responses were coded so that a $1=$ not true, $2=$ sometimes true, and $3=$ often true, so that high values indicate greater peer rejection. Peer rejection has a range of 2 to 6 and a mean of 2.45, indicating very little peer rejection in this sample.

Because child neglect has been most often associated with greater levels of serious delinquency and violence rather than minor delinquency, we use a measure of violence in our analyses. Violence was measured by a two-item composite variable in which the youth were asked if in the past year they had "got in a school/work fight" and "hit or threatened to hit another person." Responses were coded so that a $0=$ no and $1=$ yes. The range of violence is 0 to 2 with a mean of .438 , indicating that only $44 \%$ of youths in the sample had been engaged in violence in the last year. Violence, 


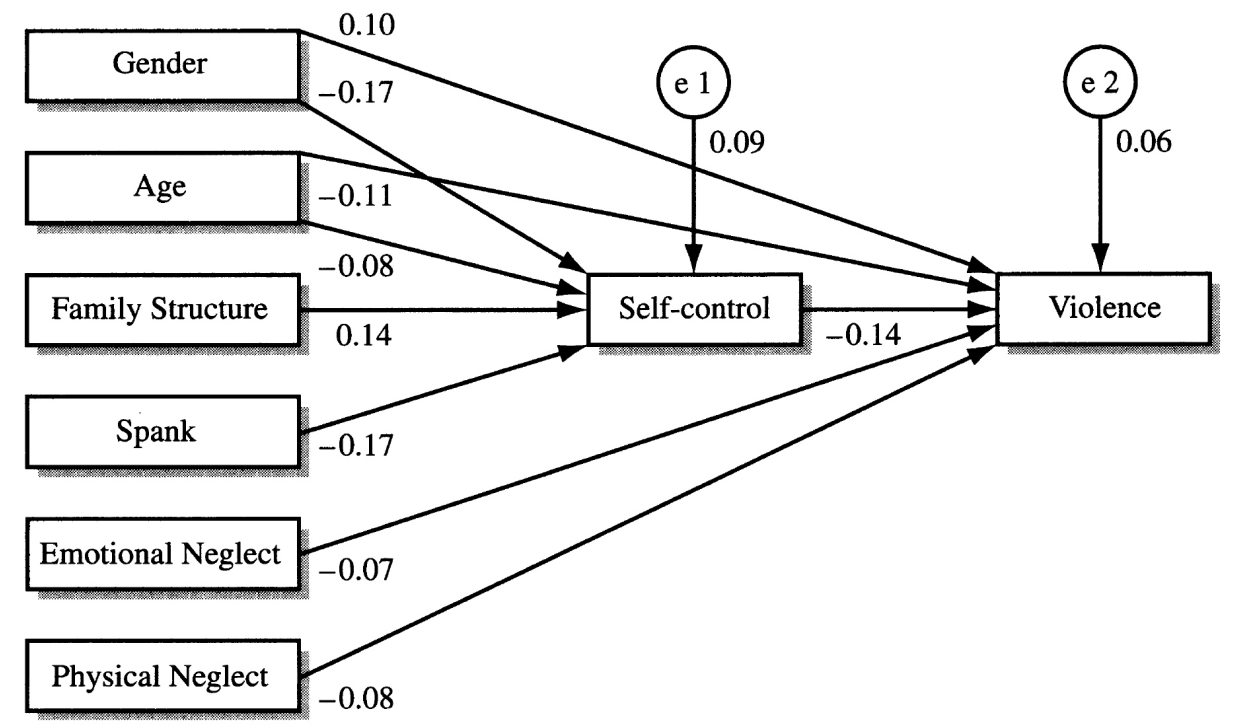

Figure 1. Child neglect, self-control, and adolescent violence $(p=.179$, RMSEA $=.021$, chisquare $=12.65$, chi-square $/ d f=1.41, \mathrm{NFI}=.999)$.

emotional neglect, physical neglect, and peer rejection were all skewed and were transformed before entering them into the analyses (Tabachnick \& Fidell, 1997, p. 85).

\section{Results}

Because we are interested in whether child neglect affects developmental processes and delinquency, we created two path models. We use multiple-least squares analysis in AMOS (Arbuckle \& Wothke, 1999) to analyze the effects of educational neglect, emotional neglect, and physical neglect on adolescent violence via self-control and peer rejection. The same initial theoretical model was specified for each analysis. The models were adjusted so that only the significant paths and correlations were retained. The results of the analyses are listed in Figures 1 and 2 and are summarized in Table 2.

We present the results of the AMOS analysis of educational neglect, physical neglect, and emotional neglect on adolescent violence via self-control in Figure 1 . We also summarize all of the significant $(p<.05$ or lower) paths for both models in Table 2. The model specified is a good fit to the data $(p=.179$; RMSEA $=.021$; chi-square/ $d f=12.65$; NFI = .999). ${ }^{4}$ Contrary to Gottfredson and Hirschi's theoretical predictions, none of the measures of child neglect were significant predictors of self-control. Perhaps not surprisingly, children who had been spanked, children from nonintact families, boys, and older youths all had lower levels of self-control. To test if the effects of neglect were confounded by measures of family structure, poverty, or spanking, we removed these three variables from the analysis and reran the model (analysis not presented). When all three of these control variables were removed, the effect of emotional neglect on self-control was significant at the $p<.10$ level, which suggested that 


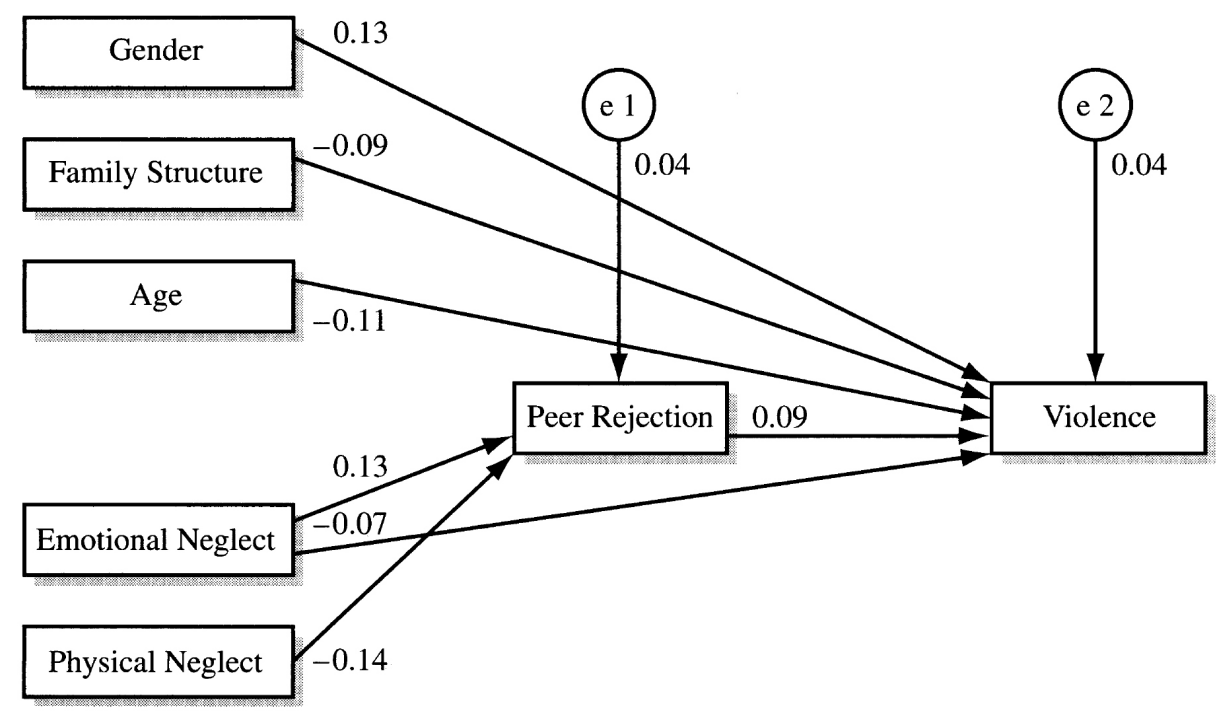

Figure 2. Child neglect, deviant peers, and adolescent violence $(p=.263$, RMSEA $=.016$, chi-square $=10.03$, chi-square $/ d f=1.25, \mathrm{NFI}=.999)$.

children who were emotionally neglected reported lower levels of self-control. Although Gottfredson and Hirschi suggest that love and affection are important precursors to self-control, parental behavior (in the form of spanking) is far more predictive of self-control.

Adolescent violence was significantly predicted by self-control $(\beta=-.14, p=.000)$, physical neglect $(\beta=-.08, p=.028)$, and emotional neglect $(\beta=-.07, p=.052)$, and the model indicated that boys and younger youths were more likely to be violent than girls and older youths $(\beta=.10, p=.002 ; \beta=-.11 ; p=.001$ respectively). According to this first model, the negative effects of child neglect, even after a 12-year lag, persist well into adolescence and are not mediated by the more proximal acquisition of self-control.

We present the results of the AMOS analysis of the effects of educational neglect, physical neglect, and emotional neglect on adolescent violence via peer rejection in Figure 2. The model fits the data well $(p=.263$; RMSEA $=.016$; chi-square $/ d f=10.02$; $\mathrm{NFI}=.999)$. Similar to past research on the relationship between neglect and peer rejection, children who were physically neglected were more likely to be rejected $(\beta=-$ $.14 ; p=.000)$; but contrary to past research, children whose mothers were emotionally attached were more likely to be rejected $(\beta=.13, p=.000)$. This is certainly anomalous, but might be an artifact of the measure of peer rejection we use. Our measure of peer rejection is a maternal report of her perceptions of the child's friendships. ${ }^{5}$ It is possible that attached mothers are disproportionately worried about the state and quality of their children's friendships and are more likely to perceive them as troubled. Without more detailed analysis into this possibility, this is only speculation.

Adolescent violence was significantly predicted by peer rejection $(\beta=.09, p=.012)$ and by emotional neglect $(\beta=-.07, p=.052)$, and was more likely among boys $(\beta=$ $.13, p=.000)$, children of nonintact homes $(\beta=-.09, p=.006)$, and younger adolescents 
Table 2. Standardized Regression Coefficients of Significant Paths

\begin{tabular}{lcccc}
\hline & $\begin{array}{c}\text { Self- } \\
\text { Control }\end{array}$ & $\begin{array}{c}\text { Peer } \\
\text { Rejection }\end{array}$ & $\begin{array}{c}\text { Violence } \\
\text { (Self-Control) }\end{array}$ & $\begin{array}{c}\text { Violence } \\
\text { (Peer } \\
\text { Rejection) }\end{array}$ \\
\hline Gender & $-.17^{* * *}$ & - & $.10^{* *}$ & $.13^{* * *}$ \\
Poverty status & - & - & - & - \\
Race & - & - & - & - \\
Age & $-.08^{*}$ & - & $-.11^{* *}$ & $-.11^{* *}$ \\
Family structure & $.14^{* * *}$ & - & - & $-.09^{* *}$ \\
Spanked in past week & $-.17^{* * *}$ & - & - & - \\
Educational neglect & - & - & - & - \\
Emotional neglect & - & $.13^{* * *}$ & $-.07^{* * * *}$ & $-.07^{* * * *}$ \\
Physical neglect & - & $-.14^{* * *}$ & $-.08^{* *}$ & - \\
Self-control & - & - & $-.14^{* * *}$ & - \\
Peer rejection & $.09^{*}$ & - & - & - \\
Squared multiple correlation & .09 & .04 & .06 & .08 \\
\hline
\end{tabular}

${ }^{*} p<.05 ;{ }^{* *} p<.01 ;{ }^{* * *} p<.001 ;{ }^{* * * *} p<.10$

$(\beta=-.11, p=.001)$. Although the long-term effect of child neglect on adolescent violence was weaker in this model (only emotional neglect was significant), we believe that given a 12-year lag, this is still an important finding. Our results also suggest that the negative effects of physical neglect on adolescent violence are mediated by children's experiences with peer rejection. This is true even when controls for poverty and family structure are included, which suggests that the ill effects of physical neglect are not limited to those children in poor families or nonintact families.

According to our findings, the negative effects of child neglect on adolescent violence, even within a community sample with self- and observer-reported measures of neglect, are significant. Although one of the measures of child neglect (emotional neglect) barely missed traditional cutoffs for significance $(p=.052)$, we believe that given a 12-year lag in the measurement of neglect and violence, we find appreciable evidence for a connection between child neglect and violence. This effect was not mediated by self-control and, in fact, self-control was not predicted by child neglect, but the effect of physical neglect on adolescent violence was mediated by experiences with peer rejection. Our research suggests that even experience with milder forms of child neglect, which may or may not result in state intervention, has detrimental effects on adolescent development and behavior.

\section{Conclusions and Discussion}

We proposed to answer two key questions with our analyses of child neglect and adolescent violence. First, do experiences with child neglect, measured by self- and observer reports, predict involvement in adolescent violence in a community sample? Second, is the relationship between child neglect and adolescent violence affected by more proximal developmental processes, such as the acquisition of self-control and peer rejection? Although we have a 12-year lag between measures of child neglect and adolescent violence, we find appreciable support for the idea that child neglect, especially physical neglect, increases the likelihood for violence later in life. We find less support for the relationship between emotional neglect and violence, but we be- 
lieve that our data indicate that there is a significant, if weaker, link. To answer our second question, we find that child neglect does not predict self-control, and self-control, while it is a significant predictor of adolescent violence, does not mediate the relationship between neglect and violence. Experiences with peer rejection, however, mediate the relationship between physical neglect and violence. Our findings suggest, similar to past research, that physically neglected children are more likely to be rejected by their peers.

Our research sheds important light on intervening developmental processes that affect the relationship between child neglect and violence. In addition, we have shown that in community samples, with self- and observer reports of neglect, the deleterious effects of neglect on adolescent development are marked. This finding is significant as it suggests that even with milder forms of child neglect, the adverse outcomes exist. There may be countless children suffering the ill effects of child neglect who may never be detected by child service workers or teachers because their neglect is not extreme. While neglect often comprises almost half of all child deaths due to maltreatment (Scannapieco \& Connell-Carrick, 2002), it is notoriously difficult to detect. Traditionally, only more severe cases of child abandonment and failure to provide food and shelter were reported to child protection services (National Research Council, 1993). Our research indicates that many children at risk for delinquency due to child neglect might be even harder to detect as their neglect may appear more benign-simply having a dirty home, not reading to your child at night, or not conversing regularly with your child.

Although we did not find support for the idea that child neglect is associated with low self-control in children, we feel that this issue is far from resolved. While Gottfredson and Hirschi maintain that love and affection are needed to form a close, affective bond between parent and child, they also suggest that this is not enough to produce self-control, but that parents must monitor, correct, and punish children's errant behavior to produce self-control in children (1990, p. 97). Our research suggests the converse, that the absence of affection and caring is not enough to allow low self-control to occur. Perhaps not surprisingly to Gottfredson and Hirschi, spanking was a very strong predictor of self-control. Children who had been spanked at age 3 to 5 reported much lower levels of self-control at age 11 to 13 than children who had not been spanked.

This finding is in keeping with Gottfredson and Hirschi's suggestion that low selfcontrol in children is most likely found when "... punishment in these families tends to be easy, short-term, and insensitive - that is, yelling, screaming, slapping, and hitting ..." (1990, p. 101) and is reflected in research that suggests a causal link between corporal punishment and child impulsivity (Straus, 1991). We also believe that the absence of a relationship between self-control and child neglect was due, in part, to the measures we employ. Had we been able to use more conventional measures of child neglect, such as withholding food, water, and daily necessities, or if we had measured child neglect as grossly lax supervision, we believe there would have been a significant relationship. As it stands, this is an important area of research for criminologists and child maltreatment researchers alike as the acquisition of self-control is an important developmental milestone.

Our research has several strengths as well as one notable weakness. The data and measures we use are both a strength and a weakness. We believe that the national, longitudinal data with mother reports, adolescent reports, and observer reports is a major strength of this research. Very little research on child maltreatment has utilized prospective, longitudinal data, and very few data sets contain data on respondents from across the country. Therefore, our findings are not limited to a particular county, 
city, or state locale but may represent the experiences of mothers, children, and adolescents in different parts of the country. Also, researchers in child maltreatment and child neglect have recently called for the use of prospective, longitudinal data into adolescence to study the long-term effects of child maltreatment, and particularly, child neglect. Researchers have also called for the use of multireporters of child neglect. We are able to do both with our data; we use prospective longitudinal data into adolescence and utilized self- and observer reports of child neglect. We believe this research adds important information on the effects of child neglect on adolescent behavior within a community sample.

However, the nature of secondary data analysis and our less than ideal measures of child neglect are limitations of the research. We were unable to measure gross lax supervision, abandonment, or the withholding of food, water, and other daily necessities that comprise traditional measures of physical child neglect. Our measures of poor physical environments are proxies for more serious forms of physical neglect. Also, the measures of emotional neglect we use, although observer ratings, do not tap into how the mothers feel (or do not feel) about their children. They are measures of maternal behavior and observer perceptions that may not adequately measure emotional neglect in the preschool years. Our measures likely underestimate the nature of the relationship between neglect, self-control, peer rejection, and violence as they underestimate the severity of neglect in this sample.

Future research on child neglect should continue to employ community samples with self- and observer reports of child neglect, but reports of child neglect should include more traditional measures of neglect, such as failure to provide food and shelter and mother's emotional connection to her children. We also propose that research on child neglect should more carefully examine measures of community and structural context as have been shown to be important predictors of adolescent development among maltreated children (Coulton et al., 1999; Korbin, 2003). Neglected children do not live in families alone, and more attention needs to be paid to the interactive relationship between child neglect and community and social contexts to explain the long-term effects of child neglect. It is possible that our measures of physical environment, even net of controls for poverty, are proxies for community disorganization. If this is true, then the community context of child neglect is particularly important for adolescent development. That said, our research indicates that even less serious forms of child neglect have long-reaching negative effects on children, their peer relationships, and their violent behavior.

\section{Notes}

1. The youngest women of the original NLSY79 sample are now 39 years old. When these women complete their childbearing, the child and young adult subsamples will be a nationally representative sample of children born to women who were born between 1960 to 1965.

2. An analysis of missing data indicated that those with missing data were more likely to be older non-White, from non-intact families, and have experienced emotional neglect. This is consistent with much of the information on other analyses of the NLSY-Child and Young Adult Data (CHRR, 2000) in which children from less stable families were more likely to either drop out of the survey or not complete specific items. Our results, then, should be viewed in light of this pattern in missing data in which we, most likely, underestimate the effects of age, race, family structure, and emotional neglect on selfcontrol, peer relations, and violence.

3. Michael Gottfredson (personal communication, 10/02) suggested that parental reports of their children's behavior should be reliable measures of self-control. He com- 
mented that, if anything, this measurement strategy underestimates the extent of low self-control in our sample, thus attenuating the effects of self-control on adolescent substance use.

4. According to Arbuckle and Wothke (1999), for good fitting models, the $p$-value should be non-significant, RMSEA should be less than .05, and NFI should be close to 1.00 .

5. In analysis not presented here, children's self-report of "its hard to make friends at this school" indicated that emotional neglect was not a significant predictor of this single measure of peer difficulties. However, because of the imprecision of this measure, which constrains it to making friends at school, we chose to use the two-item measure of peer rejection from the mother reports.

\section{References}

Arbuckle, J. L., \& Wothke, W. (1999). Amos 4.0 users guide. Chicago, IL: Small Waters Corporation.

Avakame, E. F. (1998). Intergenerational transmission of violence, self-control and conjugal violence: A comparative analysis of physical violence and psychological aggression. Violence and Victims, 13, 301-316.

Benda, B. B., \& Corwyn, R. F. (2002). The effect of abuse in childhood and in adolescence on violence among adolescents. Youth \& Society, 33, 339-365.

Bolger, K. E., Patterson, C. J., \& Kupersmidt, J. B. (1998). Peer relationships and self-esteem among children who have been maltreated. Child Development, 69, 1171-1197.

Bolger, K. E., \& Patterson, C. J. (2001). Developmental pathways from child maltreatment to peer rejection. Child Development, 72, 549-568.

Brezina, T. (1998). Adolescent maltreatment and delinquency: The question of intervening processes. Journal of Research in Crime and Delinquency, 35(1), 71-99.

Center for Human Resource Research. (2000). 1998 child \& young adult data: Users guide. Columbus, OH: The Ohio State University.

Chapple, C. L., Hope, T. L., \& Whiteford, S. W. (2004). The direct and indirect effects of parental bonds, parental drug use and self-control on adolescent substance use. Journal of Child and Adolescent Substance Abuse, 14(3), 17-38.

Coie, J. D., \& Cillessen, A. H. (1993). Peer rejection: Origins and effects on children's development. Current Directions in Psychological Science, 2, 89-92.

Coie, J. D., Dodge, K. A., Terry, R., \& Wright, V. (1991). The role of aggression in peer relations: An analysis of aggression episodes in boys' play groups. Child Development, 62, 812-826.

Coulton, C. J., Corbin, J. E., \& Su, M. (1999). Neighborhoods and child maltreatment: A multilevel study. Child Abuse \& Neglect, 23, 1019-1040.

Crouch, J. L., \& Milner, J. S. (1993). Effects of child neglect on children. Criminal Justice and Behavior, 20, 49-65.

DeMuth, S. (2004). Understand the delinquency and social relationships of loners. Youth $\mathcal{E}$ Society, 35, 366-392.

De Paul, J., \& Arruabarrena, M. I. (1995). Behavior problems in school-aged physically abused and neglected children in Spain. Child Abuse \& Neglect, 19, 409-418.

Doerner, W. G. (1988). Child maltreatment seriousness and juvenile delinquency. Youth $\&$ Society, 19, 197-234.

Egeland, B., Yates, T., Appleyard, K., \& van Dulman, M. (2002). The long-term consequences of maltreatment in the early years: A developmental pathway model to antisocial behavior. Children's Services: Social Policy, Research, and Practice, 5(4), 249-260.

Gabarino, J., \& Sherman, D. (1980). High-risk neighborhoods and high-risk families: The human ecology of child maltreatment. Child Development, 51, 188-198.

Gershater-Molko, R. M., Lutzker, J. R., \& Sherman, J. A. (2003). Assessing child neglect. Aggression and Violent Behavior, 8, 563-585. 
Gibbs, J. J., Geiver, D., \& Martin, J. S. (1998). Parental management and self-control: An empirical test of Gottfredson and Hirschi's general theory. Journal of Research in Crime and Delinquency, 35(1), 40-70.

Gottfredson, M. R., \& Hirschi, T. (1990). A general theory of crime. Stanford, CA: Stanford University Press.

Herrenkohl, T. I., Huang, B., Tajima, E. A., \& Whitney, S. D. (2003). Examining the link between child abuse and youth violence. Journal of Interpersonal Violence, 18(10), 1189-1208.

Hildyard, K. L., \& Wolfe, D. A. (2002). Child neglect: Developmental issues and outcomes. Child Abuse \& Neglect, 26, 679-695.

Hope, T. L., \& Chapple, C. L. (2004). Maternal characteristics, parenting and adolescent sexual behavior: The role of self-control. Deviant Behavior, 26(1), 25-45.

Hope, T. L., Grasmick, H. G., \& Pointon, L. J. (2003). The family in Gottfredson and Hirschi's general theory of crime: Structure, parenting, and self-control. Sociological Focus, 36(4), 291-311.

Horowitz, A. V., Spatz Widom, C., McLaughlin, J., \& Raskin White, H. (2001). The impact of childhood abuse and neglect on adult mental health: A prospective study. Journal of Health and Social Behavior; 42, 184-201.

Ireland, T. O., Smith, C. A., \& Thornberry, T. P. (2002). Developmental issues in the impact of child maltreatment on later delinquency and drug use. Criminology, 40(2), 359-399.

Kaufman, J., \& Cicchetti, D. (1989). Effects of maltreatment on school-age children's socioemotional development: Assessments in a day-camp setting. Developmental Psychology, 25, 516-524.

Korbin, J. E. (2003). Neighborhood and community connectedness in child maltreatment research. Child Abuse \& Neglect, 27, 137-140.

Kruttschnitt, C., Ward, D., \& Sheble, M. A. (1987). Abuse-resistance youth: Some factors that may inhibit violent criminal behavior. Social Forces, 66(2), 501-519.

Lemmon, J. H. (1999). How child maltreatment affects dimensions of juvenile delinquency in a cohort of low-income urban youths. Justice Quarterly, 16(2), 357-376.

Little, S. A., \& Garber, J. (1995). Aggression, depression, and stressful life events predicting peer rejection in children. Development \& Psychopathology, 7,845-856.

Luntz Weiler, B., \& Spatz-Widom, C. (1996). Psychopathy and violent behaviour in abused and neglected young adults. Criminal Behaviour and Mental Health, 6, 253-271.

Manly, J. T., Cicchetti, D., \& Barnett, D. (1994). The impact of subtype, frequency, chronicity, and severity of child maltreatment on social competence and behavior problems. Development and Psychopathology, 6, 121-143.

Maughan, A., \& Cicchetti, D. (2002). Impact of child maltreatment and interadult violence on children's emotion regulation abilities and socioemotional adjustment. Child Development, 73(5), 1525-1542.

McCord, J. (1983). A forty year perspective on effects of child abuse and neglect. Child Abuse $\mathcal{E}$ Neglect, 7, 265-270.

Mueller, E., \& Silverman, N. (1989). Peer relations in maltreated children. In D. Cicchetti \& V. Carlson (Eds.), Child maltreatment: Theory and research on the causes and consequences of child abuse and neglect (pp. 529-578). New York: Cambridge University Press.

National Research Council. (1993). Understanding child abuse and neglect, July 1993. Washington, DC: National Academy of Sciences.

Paternoster, R., \& Brame, R. (1997). Multiple routes to delinquency? A test of developmental and general theories of crime. Criminology, 35(1), 49-83.

Patterson, G. R., DeBaryshe, B. D., \& Ramsey, E. (1989). A developmental perspective on antisocial behavior. American Psychologist, 44, 329-335.

Patterson, G. R., Dishion, T. J., \& Bank, L. (1984). Family interaction: A process model of deviancy training. Aggressive Behavior; 10, 253-267.

Pope, A. W., \& Bierman, K. L. (1999). Predicting adolescent peer problems and antisocial activities: The relative roles of aggression and dysregulation. Developmental Psychology, 35, 335-346. 
Raskin White, H., \& Spatz Widom, C. (2003). Intimate partner violence among abused and neglected children in young adulthood: The mediating effects of early aggression, antisocial personality, hostility and alcohol problems. Aggressive Behavior, 29, 332-345.

Rubin, K. H., LeMare, L. J., \& Lollis, S. (1990). Social withdrawal in childhood: Developmental pathways to peer rejection. In S. R. Asher \& J. D. Coie (Eds.), Peer rejection in childhood (pp. 217-249). New York: Cambridge University Press.

Scannapieco, M., \& Connell-Carrick, K. (2002). Focus on the first years: An eco-developmental assessment of child neglect for children 0 to 3 years of age. Children and Youth Services Review, 24, 601-621.

Sedlak, A. J., \& Broadhurst, D. D. (1996). Third national incidence study of child abuse and neglect. Rockville, MD: U.S. Department of Health and Human Services.

Smith, C., \& Thornberry, T. P. (1995). The relationship between childhood maltreatment and adolescent involvement in delinquency. Criminology, 33(4), 451-479.

Stouthamer-Loeber, M., Wei, E. H., Homish, D. L., \& Loeber, R. (2002). Which family and demographic factors are related to both maltreatment and persistent serious juvenile delinquency? Children's Services: Social Policy, Research, and Practice, 5(4), 261-272.

Straus, M. A. (1991). Discipline and deviance: Physical punishment of children and other crime in adulthood. Social Problems, 38(2), 133-1 54.

Tabachnick, B. G. \& Fidell, L. S. (1997). Using multivariate statistics. New York: Harper Collins College Publishers.

Turner, M. G., \& Piquero, A. R. (2002). The stability of self-control. Journal of Criminal Justice, 30, 457-471.

Unnever, J. D., Cullen, F. T., \& Pratt, T. C. (2003) Parental management, ADHD, and delinquent involvement: Reassessing Gottfredson and Hirschi's general theory. Justice Quarterly, 20(3), 471-500.

Whitbeck, L. B., \& Hoyt, D. R. (1999). Nowhere to grow: Homeless and runaway adolescents and their families. New York: Aldine De Gruyter.

Widom, C. S. (1989). The cycle of violence. Science 244, 160-166.

Zingraff, M. T., Leiter, J., Johnsen, M. C., \& Myers, K. A. (1994). The mediating effect of good school performance on the maltreatment-delinquency relationship. Journal of Research in Crime and Delinquency, 31(1), 62-91.

Zingraff, M. T., Leiter, J., Meyers, K. A., \& Johnsen, M. C. (1993). Child maltreatment and youthful problem behavior. Criminology, 31(2), 173-202.

\section{Appendix. Items Comprising the Self-Control Scale}

Description of Items in the Self-Control Scale

How often are these statements true about your child?

Child bullies or is cruel to others.

Child is not sorry after misbehaving.

Child is impulsive, acts without thinking.

Child is restless or overactive.

Child is stubborn, sullen, or irritable.

Child has a very strong temper.

Child has trouble getting along with teachers.

Alpha $=.77$ 